\title{
HAEMOSTASIS WITH AN EASILY PREPARED STABLE THROMBIN SOLUTION
}

\author{
BY \\ LUDWIG A. STERNBERGER \\ From the Department of Pathological Physiology, Hebrew University, and the Rothschild Hadassah \\ University Hospital, Jerusalem*
}

(RECEIVEd For PUblication, MAY 18, 1948)

During physiological blood coagulation after injury the "clotting enzyme," thrombin, is always formed in excess. Such large amounts of liberated thrombin would ultimately cause extensive intravascular thrombosis, were it not for the presence of substances with antithrombic activity, which destroy the thrombin formed, partly before and partly after its action upon fibrinogen. While these substances are of great protective importance in physiological blood coagulation, they have hampered in vitro work considerably. Much difficulty has been caused by them in the quantitative determination. of prothrombin, because it has not been possible to convert prothrombin to thrombin completely in plasma or whole blood and to measure thereafter the activity of the latter in clotting fibrinogen. An undeterminable part of the thrombin formed has always been destroyed by antithrombic activity.

In the same way, the in vitro isolation of thrombin for the purpose of haemostasis has been hampered by such destruction of thrombin immediately after its formation. While American authors (Cohn and others, 1940, 1946 ; Edsall and others, 1944 ; Milstone, 1942 ; Seegers, 1940 ; Seegers and McGinty, 1942 ; Seegers and others, $1938,1945)$ have solved this problem by the isolation, instead of thrombin, of its precursor, prothrombin, and by subsequent elaborate purification of the latter to separate it from as much antithrombin as possible, yet they have not been able to remove all the antithrombin, and this is shown by the fact that their preparations are not very stable in the liquid state.

Recently it has been found that the antithrombic activity of plasma can be specifically suppressed by dilute ethyl alcohol (Sternberger, 1947), and the effect was made use of for the development of a simple two-stage method for the determination of prothrombin that is independent of any inactivators and that is thus able to determine prothrombin quantitatively (Sternberger, 1947, 1948). In the present communication preliminary experiments are reported upon the isolation and clinical use of thrombin from blood in which the antithrombic activity has been suppressed and prothrombin subsequently converted to thrombin. It will be shown that this preparation offers the following advantages over previous ones:

1. The thrombin obtained is completely free from antithrombin, not only separated from it by fractional purification as in previous methods. Therefore the thrombin is stable for many months, in the liquid state, diluted or undiluted. Other thrombin preparations are not stable once they have been diluted (Bailey, 1945 ; Glazko, 1947).

2. No elaborate purifications are necessary in the preparation of our thrombin. The procedure is, therefore, so simple that any laboratory can produce its own thrombin for surgical haemostasis. No complicated equipment is necessary.

3. During its preparation our thrombin is coprecipitated with acacia. The presence of acacia gives the thrombin a sticky consistency. This makes it possible to use thrombin solutions effectively with much smaller activity than hitherto, derived from a correspondingly smaller amount of blood.

\section{Method of Preparation of Thrombin}

Step 1: "Thrombinization."-A temperature between $16^{\circ}$ and $22^{\circ}$ C. $\left(60.8^{\circ}\right.$ to $71.6^{\circ}$ F. $)$ is maintained while the following ingredients are placed

*Present address : Sloan-Kettering Institute for Cancer Research, Memorial Cancer Center, New York. 
successively into a flask and stirred after each addition :

380 parts of 50 per cent by volume of ethyl alcohol in normal saline solution.

145 parts of normal saline solution.

25 parts of $0.2 \mathrm{M}$ calcium chloride solution.

210 parts of human blood (whole blood ; 9 parts of blood obtained by venepuncture and rendered incoagulable by addition to 1 part of $0.1 \mathrm{M}$ sodium oxalate solution).

75 parts of human milk.*

75 parts of 50 per cent by volume of ethyl alcohol in normal saline solution.

The material obtained after the lapse of about 5 to 10 minutes (crude thrombin) will clot an equal volume of human plasma in 6 to 8 seconds. It is very stable. It may be processed immediately or may be kept in the refrigerator without loss of activity for at least eight months.

The subsequent steps may be performed at a temperature between $16^{\circ}$ and $28^{\circ}$ C. $\left(60.8^{\circ}\right.$ to $82.4^{\circ}$ F.).

Step 2: Denaturation of labile blood proteins.To 32 parts of "crude thrombin" (shaken well to obtain a uniform suspension) are added 18 parts of 95 per cent ethyl alcohol by volume. The whole is shaken violently and centrifuged immediately. The supernatant fluid is decanted, and Step 3 immediately proceeded with.

Step 3: Elution.-The sediment, stirred well to break it up as completely as possible, is again dissolved in 32 parts of a 10 per cent solution of powdered acacia in normal saline and centrifuged.

Step 4 : Co-precipitation.-To 30 parts of the supernatant fluid are added 32 parts of 95 per cent of ethyl alcohol by volume and the whole is well mixed and centrifuged. The supernatant fluid is decanted and the next step immediately proceeded with.

Step 5: Resolution.-The sediment is dissolved in 3 parts of normal saline solution. This is done by wiping the sticky sediment around a glass rod and breaking it up by pressing it at the same time against the walls of the centrifuge tube. It will then dissolve easily in the relatively small volume of added liquid.

We usually dissolved the sediment of thrombin and acacia in a solution of $1: 1,000$ merthiolate (sodium

\footnotetext{
- Many samples of blood carry with them enough thromboplastin for making it unnecessary to add further thromboplastin for the conversion of prothrombin to thrombin in the presence of ethyl alcols in the blood is very irregular, so that it becomes necessary to use additional thromboplastin to obtain a dependable preparation of additional

In this preparation of thrombin from human blood human milk is

In this preparation of thrombin from human blood human milk is
used. It has been claimed that foreign protein in thrombin preparaused. It has been claimed that foreign protein in thrombin preparawarning is lacking.

Cow's milk also contains thromboplastin, but its activity is much smaller than that of human milk.
}

ethyl mercurithiosalicylate) in normal saline. When thrombin was being prepared for surgical use, sterile technique was employed from the moment of the second addition of alcohol on (in Step 4) (sterilization by 50 per cent alcohol). In this case the final thrombin and acacia solution was dissolved in 1:7,500 merthiolate in normal saline solution. All our thrombins so prepared were tested for sterility, and in none did any growth take place.

\section{Results}

The Table gives the clotting times obtained with our acacia-containing thrombin solution. No loss? of activity of the thrombin solution took place during a period of six months' storage in the ice box.

TABLE

CLOTTING TIME WITH ACACIA-CONTAINING THROMBIN SOLUTION

\begin{tabular}{|c|c|}
\hline $\begin{array}{c}\text { Dilution of thrombin } \\
\text { (after addition to test } \\
\text { plasma) }\end{array}$ & $\begin{array}{l}\text { Clotting time (second } \\
\text { (assay by adding } 0.2 \mathrm{~m} \\
\text { of diluted thrombin } \mathrm{t} \\
0.2 \mathrm{ml} \text {. of oxalated } \\
\text { human plasma) }\end{array}$ \\
\hline $\begin{array}{l}1: 2 \\
1: 6 \\
1: 10 \\
1: 20 \\
1: 40\end{array}$ & $\begin{array}{rl}2 & 1 / 2 \\
2 & \\
5 & 1 / 2 \\
10 & \\
18 & \end{array}$ \\
\hline
\end{tabular}

Because of the admixture with acacia, the thrombin preparation, when applied to a wound, will adhere to the bleeding surface. It does, therefore, as shown by clinical experience, prove effective as a haemostatic agent, although its in vitro 의 activity is less than that of some other prepara- $\rightarrow$ tions of thrombin, this corresponding to the smaller amount of blood required for its isolation. N

Our thrombin can be applied by simply placing a few drops of the gelatinous solution upon a plug $N$ of gauze. The stickiness of the acacia prevents $\omega$ the thrombin from being soaked up by the gauze,, the solution tending to adhere to its surface. Thus, it produces an effective haemostatic layer between $\mathbb{\Phi}$ gauze and bleeding wound. The fact that the pre-? paration is not soaked up by the gauze also adds to $T$ the economy of its use. The gauze covered with $\stackrel{\overrightarrow{1}}{\bar{D}}$ thrombin-acacia is applied to the wound until hae- $\stackrel{?}{?}$ mostasis is produced. It may then be removed. $\mathbb{Q}$ While a clot is produced at the interface between $\bar{\sigma}$ the thrombin-acacia and the bleeding surface, this 
clot-because of the stickiness of the preparation -does not extend beneath the surface of the gauze, and does not, therefore, cause fresh laceration and fresh bleeding when it is subsequently removed (a difficulty encountered by Tidrick and others (1943) in the use of their preparation with cotton plugs and bits of gauze). Bleeding also recurs, as reported by Bailey and others (1945), if fibrin foam (Cohn and others, 1940, 1946 ; Edsall and others, 1944) applied to a wound with thrombin is removed after production of haemostasis.

The stability of our preparation in the liquid form makes it possible to use a few drops of thrombin for one purpose, and to store the remainder of the bottle in the refrigerator until new requirements arise. This further adds to the economy of the preparation, in contrast to those products that are supplied in a powdered form and cannot be stored after once having been dissolved. Even a few hours' storage at subtropical room temperature $\left(26^{\circ}\right.$ to $28^{\circ} \mathrm{C}$. $\left(78.8^{\circ}\right.$ to $82.4^{\circ} \mathrm{F}$.) in our laboratory and hospital at the time this preparation was being developed and tried clinically) does not impair the effectiveness of our preparation. The thrombin prepared by Cohn and his team is rapidly destroyed at temperatures higher than room temperature (Bailey and others, 1945).

The thrombin described here has been used by Dr. Lachmann, Chief of the Otolaryngology Department of this hospital. He reports as follows:

"The thrombin was used in twenty tonsillectomies and in eight Caldwell-Luc's operations on the maxillary sinus. In tonsillectomies, at the completion of the operation a tampon of gauze covered with a few drops of thrombin solution was applied with slight pressure for 1 to 2 minutes to the tonsillar bed. It was then removed. At this time the wound was dry in every instance, including cases in which bleeding before application of thrombin was very strong. Only spurting blood vessels were ligated before using the thrombin. Many cases would have required careful ligation, had thrombin not been used.

In Caldwell-Luc's operation on the maxillary sinus, 1 to $3 \mathrm{ml}$. of thrombin were instilled upon completion of the operation. Bleeding always stopped within a short time ( 2 to 5 minutes). The cavity remained without tampon. Only in one case, which showed very heavy haemorrhage because of hypertension $(270 / 140 \mathrm{~mm}$. $\mathrm{Hg})$, the cavity. was packed lightly with gauze upon which thrombin had been placed. This stopped the haemorrhage at once, without recurrence upon removal of the tampon the following day."

The thrombin was also used in a case of dicoumarol hypoprothrombinemia (Sternberger, 1948) (prothrombin: 12.5 per cent determined by the stabilized thrombin method (Sternberger, 1947)). The patient started to bleed from the operation wound eleven days after the second stage of Lahey's abdominal-perineal resection of the rectum (Dr. Joseph). Haemostasis with thrombin was immediate.

\section{Summary}

The principle of the suppression of the antithrombic activity of plasma by ethyl alcohol was applied to the development of a new method for the isolation of thrombin. The simplicity of the method makes it possible for any clinical laboratory to prepare thrombin for its own use for surgical haemostasis. The thrombin prepared is stable in the liquid form. The clinical use of the preparation in haemorrhage and the advantages of admixture of acacia with thrombin have been discussed.

I wish to thank Prof. E. Wertheimer, Chief of the Department of Pathological Physiology, Hebrew University, and Director of the Chemical Laboratory, Rothschild Hadassah University Hospital, for his unfailing counsel during this investigation. I am grateful to Dr. Lachmann, Chief of the Otolaryngological Department, Rothschild Hadassah University Hospital, for his readiness to make the first clinical trials with the preparation described, and for his advice during its surgical application.

\section{REFERENCES}

Bailey, O. T., Ingraham, F. D., Swenson, O., Lowrey, J. J., and Bering, E. A. (1945). Surgery, 18, 347.

Cohn, E. J., Luetscher, J. A., Jr., Oncley, J. L., and Armstrong, S. H., Jr., Davis, B. D. (1940). J. Amer. Chem. Soc., 62, 3396.

Cohn, E. J., Strong, L. E., Hughes, W. L., Jr., Mulford, D. J., Ashworth, J. N., Melin, M., and Taylor, H. L. (1946). J. Amer. Chem. Soc., 68, 459.

Edsali, J. T., Ferry, R. M., and Armstrong, S. H., Jr. (1944). J. clin. Invest., 23,557 .

Glazko, A. J. (1947). Proc. Soc. exp. Biol., N.Y., 64, 444.

Milstone, H. (1942). J. gen. Physiol., 25, 679.

Seegers, W. H. (1940). J. biol. Chem., 136, 103.

Seegers, W. H. (1940). J. biol. Chem., 136, 103. . (1938). J. biol. Chem., 123, 751 .

Seegers, W. H., and McGinty, D. A. (1942). J. biol. Chem., 146, 511. Seegers, W. H., Loomis, E. C., and Vandenbelt, J. M. (1945). Arch. Biochem., 6, 85

Sternberger, L. A. (1947). Brit. J. exp. Path., 28, 168

Sternberger, L. A. (1948). In press.
Tidrick, R. T., Seegers, W. H., and Warner, E. D. (1943). Surgery 14, 191 . 